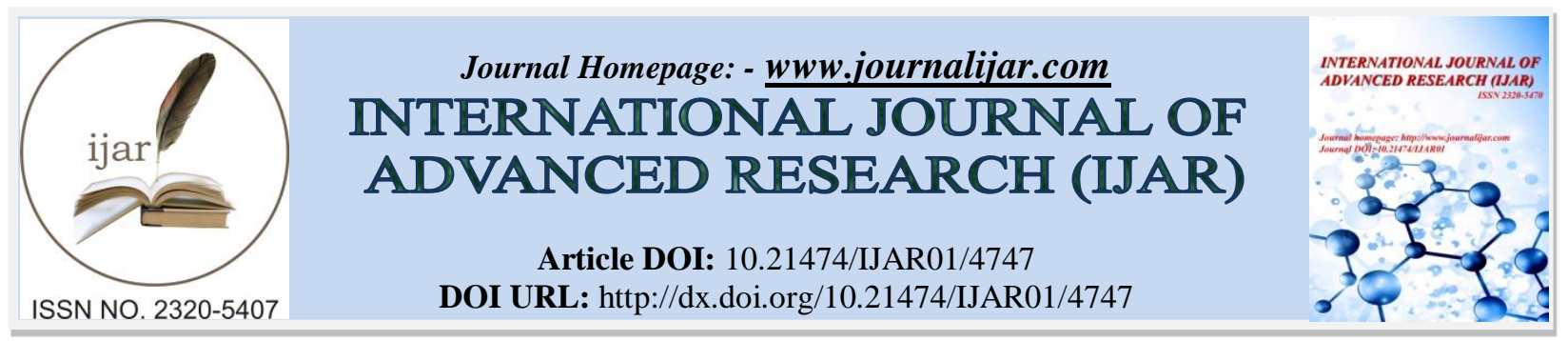

RESEARCH ARTICLE

\title{
TEACHERS PERSONALITY COMPETENCE AND ITS INFLUENCE ON MORAL BEHAVIOR BASED ON GENDER.
}

I Made Putrawan.

State University of Jakarta, Indonesia.

\section{Manuscript Info}

Manuscript History

Received: 5 May 2017

Final Accepted: 7 June 2017

Published: July 2017

Key words:-

big-five personality, factor loading, eigen value, gender.

\section{Abstract}

One of the teachers competencies is personality which is uneasy to measure. Comparing to other teachers competencies, pedagogy, social. and professional, this personality competence is rather more difficult to measure. That is why. for this purpose, it has been scientifically developed teachers personality instrument by applying big-five personality (Colquitt. et. al.. 2017) concepts and try to relate it to teachers moral behaviour based on gender. Considering research objectives, survey method used by involving around 91 teachers selected randomly. Personality instrument developed based on five factors; Openness, Conscientiousness, Extraversion, Agreeableness, and Neuroticism/Emotional stability, with five scale, from most accurate to less accurate (20 items). Some indicators for measuring teachers moral behaviour was also developed (32 items). Research results revealed that all personality items have high validity and only 11 items measuring moral behaviour were omitted, because its low validity. Reliability, however, for both instruments were high. .452 for personality and .802 for moral behaviour. There was no means difference between male and female teachers personality and moral behaviour. Moreover. there was no eigen-values and factor loading differences between male and female teachers personality. Its construct validity has been confirmed by empirical finding where all factors loading were > .30 (Hair. et. al.. 2010). Teachers moral behaviour. Moreover, was not significantly determined by personality. Therefore, it could be concluded that teachers personality instrument might be validated based on gender and extraversion factor could be an indicator that gender did not affect teachers personality instrument development based on big-five personality dimensions.

Copy Right. IJAR, 2017, All rights reserved.

\section{Introduction:-}

Today we are facing so many problems like terrorism, poverty and population problem. It is necessary to inculcate moral values in curriculum. Education is an effective weapon. Education is a weapon, whose effect depends on who holds it is his hands and at whom it is aimed (Joseph Stalin). Hogan (1973) believes that moral behavior is determined by five factors: (1) Socialization: becoming aware as a child of society's and parents' rules of conduct for being good. (2) Moral judgment: learning to think reasonably about our own ethics and deliberately deciding on our own moral standards. (3) Moral feelings: the internalization of our moral beliefs to the degree that we feel shame 
and guilt when we fail to do what we "should." (4) Empathy: the awareness of other people's situation. feelings. and needs so that one is compelled to help those in need. (5) Confidence and knowledge: knowing the steps involved in helping others and believing that one is responsible for and capable of helping.

The main causes of moral degeneration are: Lack of respect for the sanctity of human life. breakdown of parental control of children in families, lack of respect for authority, seen through the brazen breaking of the law and total disregard for rules and regulations, crime and corruption, abuse of alcohol and drugs, abuse of women and children, and other vulnerable members of society, lack of respect for other people and property. ${ }^{1}$

This article proposes and tests a social-cognitive framework for examining the joint influence of situational factors and the centrality of moral identity on moral intentions and behaviors. The authors hypothesized that if a situational factor increases the current accessibility of moral identity within the working self-concept, then it strengthens the motivation to act morally. In contrast, if a situational factor decreases the current accessibility of moral identity, then it weakens the motivation to act morally. The authors also expected the influence of situational factors to vary depending on the extent to which moral identity was central to a person's overall self-conception.

In related to the article entitled "Moral Emotions and moral Behavior," Tangney. et. al. reported that "moral emotions represent a key element of our human moral apparatus, influencing the link between moral standards and moral behavior. $^{2}$

On the other occasion, Schwitzgebel \& Rust gave an additional statement that "many people might be willing to grant the following: moral reflection tend to promote moral behavior, and professional ethicist are on average both more prone to and more skilled at moral reflection than non-ethicists". 3

Related to Personality, according to Moorhead \& Griffin, personality is a set psychological traits which relatively stable that is able to distinguish someone from another. Even still debatable, those traits inherent from his/her parents which is called "the nature argument," or has been influenced by their environment which is called "the nurture argument".

In reality, it indicates that both either biological factors or environmental factors pays important role in determining personality. A psychologist has identified a thousand of human personality traits which distinguish someone with the others. There are five traits which is related to the organizational behavior called "big five personality traits" which define as a set of basic characteristics relevant to the organization. ${ }^{4}$

Those "Big five" is as follows: 1) Agreeableness: ability to understand others; 2) Conscientiousness: related to several goals which everyone focus on; 3) Negative emotionality: low in this trait characterized by "relatively poised, calm, resilient, and secure," but when it is high it is more "excitable," unsecure, reactive, not mood. So, for those who has "less negative emotionality" would be enable for managing stress. pressure and work tension; 4) Extraversion reflected by one' trait which is sociable), talkative, assertive, and easier to communicate. The opposite is Introvert; 5) Openness reflected by the strength in believing and possess the range of interest. These traits consist of intention to accept new ideas. change his/her own ideas, trust, and attitude in responding new information.

In addition to this. McShane \& Glinow stated that personality is "the relatively enduring pattern of thought. emotions. and behaviors that characterize a person, along with psychological processes behind those characteristics." This definition is more depth because it talked about thought. besides emotion and behavior as well. Almost all of definitions tend to describe personality which distinguishes ones with the others. ${ }^{5}$

Another definition which is almost the same was given by Andre. but Andre involves one of the personality concepts called locus of control (LOC). LOC, according to Andre is measuring about to what extend each of individual believe that they are able to control some events that influence them. There are two type of LOC, first is internal LOC which tend to believe that all events facing human being as a result of his/her own behavior and actions, whereas external LOC depicts the tendency to believe the faith, chance and other powerful things will be determined by those events. ${ }^{6}$

Personality. as defined by Greenberg. is pattern of behavior. thought and emotion which relatively unique and stable that reflected by individual that differentiate with other and this characteristic is very important for job. Personality 
is also presumably as one of determinant factors which affect behavior, according to Greenberg this process called "interactionist perspective".

Related to the concept of "big five" described by Moorhead \& Griffin, Greenberg applied the same name as well. but with a different term i.e. "big five dimensions of personality." On the other hand, Andre called by using another term "big five personality profile" and the name of all dimensions are still the same. However, Greenberg called "emotional stability" instead of "negative emotionality" just like what has been proposed by Moorhead \& Griffin above.

Other term given by Mc. Shane \& Glinow, which called "five factor model of personality" or "big-five personality" which completely described those indicators for each dimension. ${ }^{5}$ On the other occasion, Ivancevich, Konopaske \& Matteson stated that personality is related to a set of person' feeling and behavior that is relatively stable which significantly formed by genetic factors and environment. They, then, stated that personality as a result of natural factors (nature) and environmental factors (nurture). ${ }^{8}$

Moreover. Colquitt. et.al. described more detail and complete about personality which according to them that personality is closely related to the structure and traits (propensities) belong to each person that depicts the pattern of human characteristic such as thought. emotion and behavior. Personality creates person' social reputation for example, the way a person behave which could be perceived by his/her family. friends. employees and even by supervisor. ${ }^{9}$

Therefore, Colquitt et.al. admitted that personality "captures what people are like". on the other hand. ability "captures what people can do." Moreover, Colquitt. et.al. defines "traits" as a regular tendency of each person in responding the environment such as "traits". In this case, Colquitt. et.al. stated that environmental factor could be called as "cultural values" which defined as sharing trust that will determine a person' behavior at a certain culture. ${ }^{9}$

\section{Research methodology:-}

The objective of this research is aim at obtaining information related to teachers personality instrument development by validating big-five personality factors based on gender and its influence on teachers moral behavior. In order to achieve this objective, a survey method has been applied by involving 91 teachers from all school level, in Padang. West Sumatra.

There were two instruments used for measuring personality and moral behavior. Personality instrument (20 items) has been developed based on big-five personality which usually used for measuring individual at work place. It consisted of five factors which derived from a million of human traits, namely; openness, conscientiousness, extraversion, agreeableness, and emotional stability. Five scales used, in this case, with five categorical, ranging from most accurate to less accurate with 5-1 scoring. There were 32 items has been developed for measuring teachers moral behavior based on Hogan (1973) dimensions such as; (1) Socialization. (2) Moral judgment. (3) Moral feelings. (4) Empathy. (5)) Confidence and knowledge.

It was found that there were 11 items were not valid because its item validity lower than .206 and its reliability was .725. But when it was calculated again after 11 items were omitted, its reliability became .802 . Reliability for personality was .452 and its construct validity has been analyzed by factor analysis (CFA) with varimax rotation. Considering statistical tools, regression and correlation analysis applied to find out whether personality influence teachers moral behavior.

\section{Research Findings and Discussion:-}

Based on descriptive statistics analysis. it was found that there was no significant difference between male and female teachers personality since the difference between its means was only slight difference. Means for male teachers personality was $64.43(\mathrm{SE}=1.24)$ whereas female teachers personality was $65.80(\mathrm{SE}=.83)$ which female teachers have higher means personality competence than male teachers. It means that female teachers were higher than male in term of their conscientiousness, agreeableness, neuroticism, openness, and extraversion. Empirically, however, the difference was not supported by strong data which, in this study, fail to reject the null hypothesis. This was an evidence that in term of teachers personality might be not influenced by gender. ${ }^{12}$ 
Nevertheless, for teachers moral behavior, there was significant difference between male teachers and female teachers moral behavior. Means for male teachers moral behavior was 123.14 ( $\mathrm{SE}=2.00)$ meanwhile female teachers was $129.38(\mathrm{SE}=.99)$. Since the difference was around 6.24 , when verified by t-test at .001 , it still this difference was strongly significant. For female teachers moral behavior. as the nature of woman, they have higher empathy, negotiation skills, socialization, etc. which tend to be affected by, hypothetically, a characteristics being a woman.

Related to personality factors which has been analyzed by factor analysis. it was found that each factor loading. as a whole (combine male and female data), only two factors have eigen value higher than 1.00 (see table 3 below).

Therefore, it could be rotated and its factor loading could be seen from table 4 below, after rotation. From this table 1 showed that there were two factor i.e. Conscientiousness and Openness have lower factor loading of .30 at component $1 .{ }^{10}$ but fortunately, they have high factor loading on component 2, so in measuring personality, two of them could be taken into consideration for not being omitted from the scale. Visually. it could be seen on fig. 1 below.

Table 1:- Rotated Component Matrix

\begin{tabular}{|l|l|l|}
\hline \multirow{2}{*}{} & Component \\
\cline { 2 - 3 } & 1 & 2 \\
\hline Conscientiousness & -.077 & .780 \\
\hline Agreeableness & .638 & .379 \\
\hline Neuroticism & .674 & .243 \\
\hline Openness & .297 & .585 \\
\hline Extraversion & .759 & -.259 \\
\hline Extraction Method: Principal Component Analysis. Rotation Method: \\
Varimax with Kaiser Normalization.
\end{tabular}

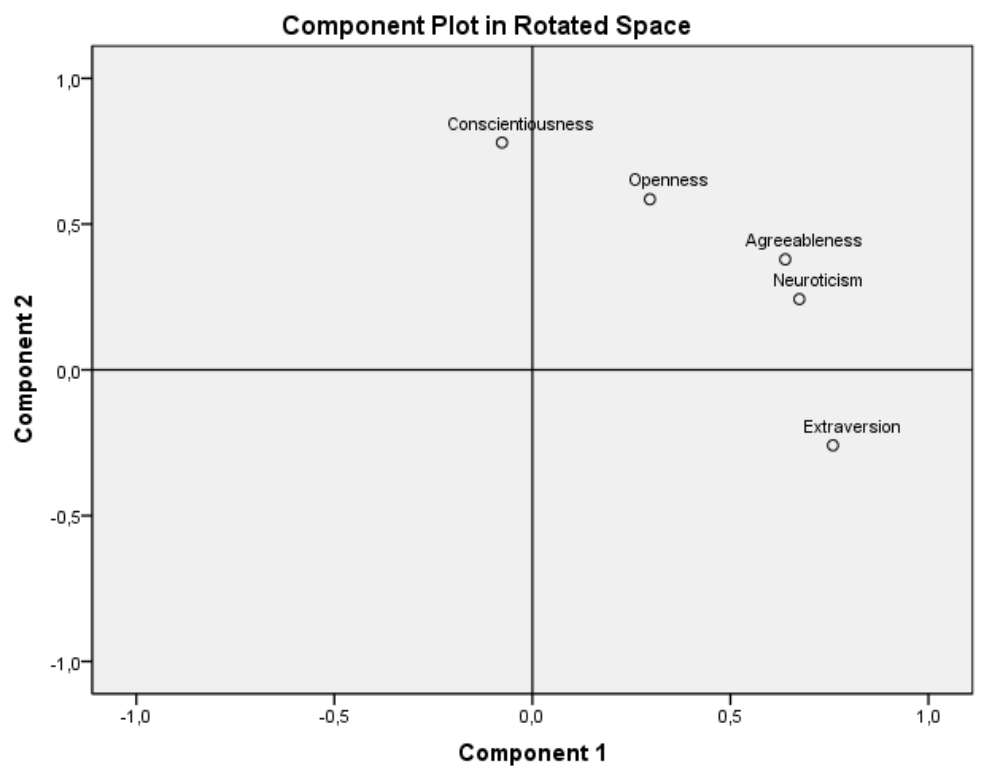

Figure 1:- Position of factors on two Components after rotation

If factor analysis conducted for male and female teachers personality, separately, the results showed that both male and female have two components due to its eigen value higher than $1.00 .{ }^{10}$ For male teachers personality, there was only Agreeableness factor has lower factor loading on component 1 (see table 2). after rotation (see fig. 2 below). 
Table 2:- Rotated Component Matrix (male teachers)

\begin{tabular}{|l|l|l|}
\hline \multirow{2}{*}{ Conscientiousness } & Component & 2 \\
\cline { 2 - 3 } & 1 & .026 \\
\hline Agreeableness & .495 & .896 \\
\hline Neuroticism & .243 & .211 \\
\hline Openness & .841 & -.188 \\
\hline Extraversion & .669 & -.641 \\
\hline Extraction Method: Principal Component Analysis. Rotation Method: Varimax with Kaiser Normalization. \\
\hline
\end{tabular}

Table 3:- Total Variance Explained

\begin{tabular}{|c|c|c|c|c|c|c|c|c|c|}
\hline \multirow[t]{2}{*}{$\begin{array}{l}\text { Compone } \\
\mathrm{nt}\end{array}$} & \multicolumn{3}{|c|}{$\begin{array}{l}\text { Initial } \\
\text { Eigenvalues }\end{array}$} & \multicolumn{3}{|c|}{$\begin{array}{l}\text { Extraction Sums of } \\
\text { Squared Loadings }\end{array}$} & \multicolumn{3}{|c|}{$\begin{array}{l}\text { Rotation Sums of } \\
\text { Squared Loadings }\end{array}$} \\
\hline & $\begin{array}{l}\text { Tota } \\
1\end{array}$ & $\begin{array}{l}\text { \% of } \\
\text { Varianc } \\
\mathrm{e}\end{array}$ & $\begin{array}{l}\text { Cumulativ } \\
\text { e } \%\end{array}$ & $\begin{array}{l}\text { Tota } \\
1\end{array}$ & $\begin{array}{l}\text { \% of } \\
\text { Varianc } \\
\mathrm{e}\end{array}$ & $\begin{array}{l}\text { Cumulativ } \\
\text { e } \%\end{array}$ & $\begin{array}{l}\text { Tota } \\
1\end{array}$ & $\begin{array}{l}\% \text { of } \\
\text { Varianc } \\
\mathrm{e}\end{array}$ & $\begin{array}{l}\text { Cumulativ } \\
\text { e } \%\end{array}$ \\
\hline 1 & 1.73 & 34.685 & 34.685 & 1.73 & 34.685 & 34.685 & 1.53 & 30.630 & 30.630 \\
\hline 2 & 1.01 & 20.339 & 55.025 & 1.01 & 20.339 & 55.025 & 1.22 & 24.394 & 55.025 \\
\hline 3 & .916 & 18.312 & 73.337 & & & & & & \\
\hline 4 & .738 & 14.763 & 88.100 & & & & & & \\
\hline 5 & .595 & 11.900 & 100.000 & & & & & & \\
\hline
\end{tabular}

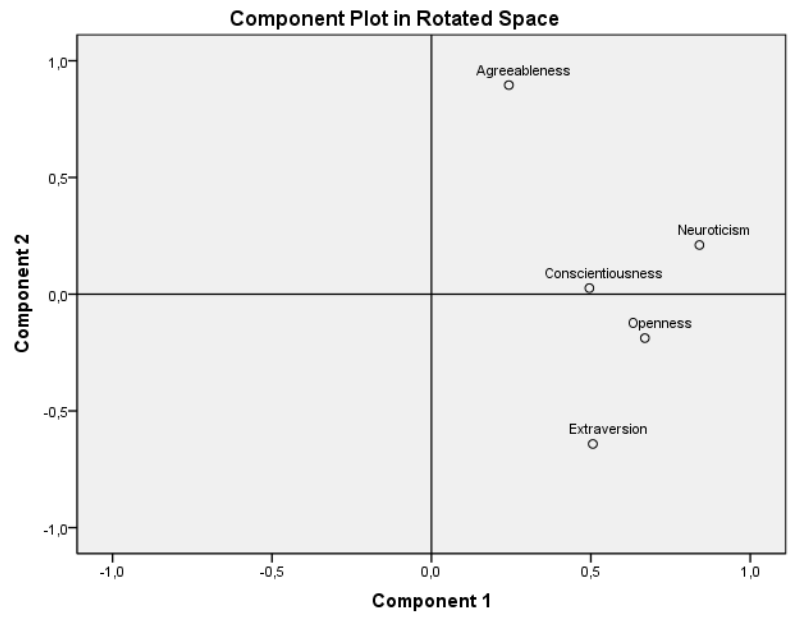

Figure 2:- Position of factors for Male Teachers Personality (after rotation)

Comparing to male teachers, female teachers personality has a consistency with the total data (male and female data) where two factors i.e. Conscientiousness and Openness were the only factors have lower factor loading than .30 , after rotation was carried out (see table 3 ).

The interesting finding was that for both male and female teachers personality, position of extraversion factor was always at the outside of two components on positive quadrant (see fig 2 and 3). This means that only this factor has been affected strongly by gender equality, this factor is not discriminated by gender. ${ }^{11}$

Table 4:- Rotated Component Matrix (female teachers)

\begin{tabular}{|l|l|l|}
\hline \multirow{2}{*}{} & Component \\
\cline { 2 - 3 } & 1 & 2 \\
\hline Conscientiousness & -.075 & .734 \\
\hline Agreeableness & .714 & .409 \\
\hline Neuroticism & .632 & .182 \\
\hline
\end{tabular}




\begin{tabular}{|l|l|l|}
\hline Openness & .268 & .660 \\
\hline Extraversion & .791 & -.224 \\
\hline Extraction Method: Principal Component Analysis. \\
Rotation Method: Varimax with Kaiser Normalization. \\
\hline
\end{tabular}

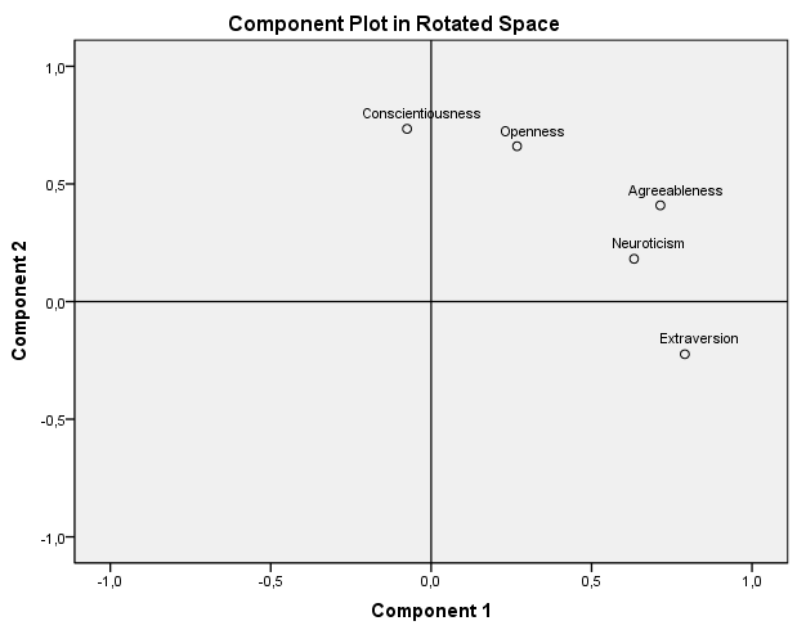

Figure 3:- Position of factors for Female Teachers

Another finding, unfortunately, revealed that there was no empirical evidence showed that teachers personality determined moral behavior due to its correlation coefficient was only .058. It meant that variation which occurred on teachers moral behavior could not be explained empirically by teachers personality. Moreover, if personality factors break down into five factors separately, none of those factors has significant correlation with teachers moral behavior, therefore, it is probably teachers moral behavior might be predicted by other factors which beyond consideration of this research.

\section{Conclusion:-}

Some conclusions could be formulated based on these findings. 1) Teachers personality could be validated its construct validity which was not affected by gender. Therefore, in developing teachers personality instrument based on big-five personality, it is suggested not to separate between male and female teachers in order to find unidimensional instrument that indicated by its high in internal consistency. In this case, female teachers has higher consistency than male teachers; 2) Gender did not affect teachers personality and moral behavior as well due to there was no means difference found between two variables; 3) There was no evidence yet empirically that personality determined teachers moral behavior, to my understanding that moral behavior, in this case, is not similar to concept of behavior in general as depicted by Greenberg (2010) above. Moral behavior might be closely understood as close as empathy and other feeling or human emotions which needed further in depth research to be carried out scientifically.

\section{References:-}

1. N. Reddy, Important of Value Education, http://ezinearticles.com/?Importance-of-ValueEducation\&id=382747. 2006.

2. J. P. Tangney. J. Stuewig. and D. J. Mashek, "Moral Emotions and Moral Behavior", Annual Report Psychology, 58, 2007. 345-72. 2007.

3. E. Schwitzgebel and J. Rust, "The Moral Behavior of Ethicists: Peer Opinion", Mind. 118. October 2009. 472,

4. R.W. Griffin and G. Moorhead, Organizational Behavior Managing People and Organizations (USA. SouthWestern, 2010)

5. S. L. McShane and M. A. Von Glinow, Organizational Behavior (Boston. Mass.: Irwin/McGraw-Hill. 2015).

6. R. Andre, Organizational Behavior: An Introduction to Your Life in Organizations (New Jersey: Pearson,2008)

7. Greenberg. Jerald, Managing Behavior in Organization, Boston: PEARSON, 2010.

8. Ivancevich. John M.. Robert Konopaske. M.T.Matteson, Organizational Behavior and Management. Irwin: McGraw Hill, 2014. 
9. Colquitt. et.al., Organizational Behavior: Improving Job Performance and Organizational Commitment (McGraw-Hill, 2017).

10. Hair. et.al.. Multivariate Statistics Analysis. (Boston Mass.: Pearson Prentice-Hall. 2010).

11. Venus. A Solar, "Gender and Natural Resource Consumption", International Journal of Environmental Science and Development. 2(5), 2011.

12. Putrawan. I Made, "Measuring Teachers Personality by Applying Big-Five Personality Based on Teachers' Gender and School Level: A Comparative Analysis," Comparative Education Bulletin, Vol 15 (1), p. 60, 2013. 